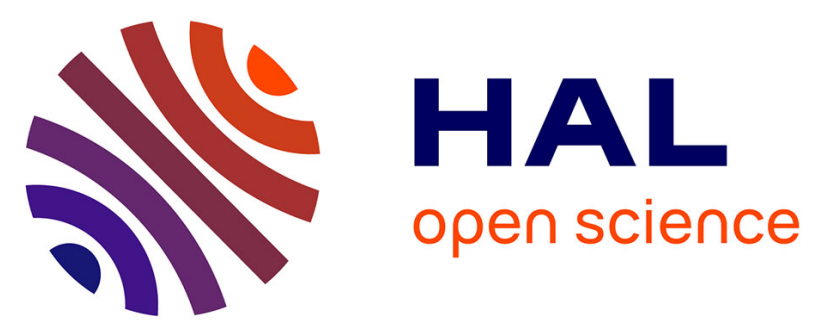

\title{
Appendicular skeletal muscle mass is the strongest independent factor associated with femoral neck bone mineral density in adult and older men
}

Hubert Blain, Audrey Jaussent, Eric Thomas, Jean-Paul Micallef, Anne-Marie Dupuy, Pierre L. Bernard, Denis Mariano-Goulart, Jean-Paul Cristol, Charles Sultan, Michel J. Rossi, et al.

\section{To cite this version:}

Hubert Blain, Audrey Jaussent, Eric Thomas, Jean-Paul Micallef, Anne-Marie Dupuy, et al.. Appendicular skeletal muscle mass is the strongest independent factor associated with femoral neck bone mineral density in adult and older men. Experimental Gerontology, 2010, 45 (9), pp.679. 10.1016/j.exger.2010.04.006 . hal-00615130

\author{
HAL Id: hal-00615130 \\ https://hal.science/hal-00615130
}

Submitted on 18 Aug 2011

HAL is a multi-disciplinary open access archive for the deposit and dissemination of scientific research documents, whether they are published or not. The documents may come from teaching and research institutions in France or abroad, or from public or private research centers.
L'archive ouverte pluridisciplinaire HAL, est destinée au dépôt et à la diffusion de documents scientifiques de niveau recherche, publiés ou non, émanant des établissements d'enseignement et de recherche français ou étrangers, des laboratoires publics ou privés. 


\section{Accepted Manuscript}

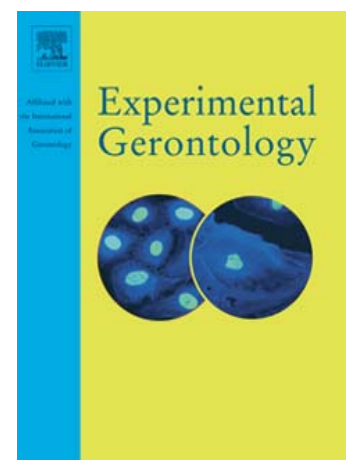

Appendicular skeletal muscle mass is the strongest independent factor associated with femoral neck bone mineral density in adult and older men

Hubert Blain, Audrey Jaussent, Eric Thomas, Jean-Paul Micallef, AnneMarie Dupuy, Pierre L. Bernard, Denis Mariano-Goulart, Jean-Paul Cristol, Charles Sultan, Michel Rossi, Marie-Christine Picot

PII: $\quad$ S0531-5565(10)00168-3

DOI: $\quad$ doi: $10.1016 /$ j.exger.2010.04.006

Reference: $\quad$ EXG 8741

To appear in: $\quad$ Experimental Gerontology

Received date: 22 December 2009

Revised date: $\quad 7$ April 2010

Accepted date: 19 April 2010

Please cite this article as: Blain, Hubert, Jaussent, Audrey, Thomas, Eric, Micallef, Jean-Paul, Dupuy, Anne-Marie, Bernard, Pierre L., Mariano-Goulart, Denis, Cristol, Jean-Paul, Sultan, Charles, Rossi, Michel, Picot, Marie-Christine, Appendicular skeletal muscle mass is the strongest independent factor associated with femoral neck bone mineral density in adult and older men, Experimental Gerontology (2010), doi: 10.1016/j.exger.2010.04.006

This is a PDF file of an unedited manuscript that has been accepted for publication. As a service to our customers we are providing this early version of the manuscript. The manuscript will undergo copyediting, typesetting, and review of the resulting proof before it is published in its final form. Please note that during the production process errors may be discovered which could affect the content, and all legal disclaimers that apply to the journal pertain. 


\section{CLINICAL INVESTIGATION}

\section{Appendicular skeletal muscle mass is the strongest independent factor associated with femoral neck bone mineral density in adult and older men}

Hubert Blain ${ }^{\mathrm{a}, *}$, Audrey Jaussent ${ }^{\mathrm{b}}$, Eric Thomas ${ }^{\mathrm{c}}$, Jean-Paul Micallef ${ }^{\mathrm{d}}$, Anne-Marie Dupuy $^{\mathrm{e}}$, Pierre L. Bernard ${ }^{\mathrm{d}}$, Denis Mariano-Goulart ${ }^{\mathrm{f}}$, Jean-Paul Cristol ${ }^{\mathrm{e}}$, Charles Sultan ${ }^{\mathrm{g}}$, Michel Rossi ${ }^{\mathrm{f}}$, Marie-Christine Picot ${ }^{\mathrm{b}}$

${ }^{a}$ Department of Geriatrics, University Hospital of Montpellier; Efficiency and Deficiency Laboratory Montpellier, EA 2991, University of Montpellier 1, France

${ }^{\mathrm{b}}$ Department of Medical Information, University Hospital of Montpellier, University of Montpellier 1, France

${ }^{\mathrm{c}}$ Department of Rheumatology, University Hospital of Montpellier, University of Montpellier 1, France

${ }^{\mathrm{d}}$ Efficiency and Deficiency Laboratory Montpellier, EA 2991, UFR STAPS, University of Montpellier 1, France

${ }^{\mathrm{e}}$ Department of Biochemistry, University Hospital of Montpellier, University of Montpellier 1, France

${ }^{\mathrm{f}}$ Department of Nuclear Medicine, University Hospital of Montpellier, University of Montpellier 1, France

${ }^{g}$ Unit of Hormonology and Pediatric Endocrinology and Gynecology, University Hospital of Montpellier, University of Montpellier 1, France

Funding for this research was provided by the French Ministry of Health (Projet Hospitalier de Recherche Clinique, UF-7606).

Running title : Appendicular muscle mass and femoral neck BMD in men

Corresponding author. Address: Service de Gériatrie, Centre de Prévention et de Traitement des Maladies du Vieillissement, CHU Montpellier, 39 avenue Charles Flahault, 34295 Montpellier Cedex 5, France. Tel: +33-467-336-790; fax: +33-467-336-887.

E-mail address: h-blain@chu-montpellier.fr (H. Blain) 


\section{ABSTRACT}

The relationship between bone mass and muscle mass may be due to the site-specific effects of loading on bone in adults and to lifestyle, nutritional, and hormonal factors. Another hypothesis is that the maintenance with aging of both appendicular muscle and bone mass may be determined by factors independent of all these previous factors, including genetic factors. In 160 healthy men aged 20 to 72 years, we recorded femoral neck bone mineral density (FN BMD), relative appendicular skeletal muscle mass [RASM; appendicular skeletal muscle mass $(\mathrm{kg})$ /height $(\mathrm{cm})$ ], age, body mass, maximum grip and knee extension strength, lifetime physical activities, calcium intake, tobacco smoking, and serum parathyroid hormone (PTH), estradiol (E2), free testosterone, dehydroepiandrosterone sulphate (DHEAS), insulin-like growth factor (IGF-I), sex hormone-binding globulin (SHBG), calcium, 25(OH) vitamin D, albumin, and creatinine clearance. The correlation between FN BMD and RASM (that includes upper and lower limb muscle mass) was of slightly greater magnitude than that between FN BMD and the relative upper limb muscle mass and between FN BMD and the relative leg muscle mass $(\mathrm{r}=$ $\underline{0.39 ;} \mathrm{p}<0.001$ versus $\mathrm{r}=0.36 ; \mathrm{p}<0.001$ and $\mathrm{r}=0.34 ; \mathrm{p}<0.001$, respectively). The stepwise multiple linear regression model showed that FN BMD was significantly associated with RASM (15\% of FN BMD variance, p<0.0001), age (10\% of FN BMD variance, $\mathrm{p}<0.0001$ ), physical activities from age $11-20$ years (5\% of FN BMD variance, $\mathrm{p}<0.01$ ), and blood PTH, IGF-I, and creatinine clearance, $(2 \%, 2 \%$, and $1 \%$ of FN BMD variance, respectively, $\mathrm{p}<0.05)$. These results show that RASM, with ASM measured by DXA, is the strongest factor associated with FN BMD in men. It remains to be determined whether assessing RASM by anthropometric methods would help screening adult men at risk of low FN BMD. Furthermore, since RASM is associated with FN BMD independently of appendicular skeletal loads and other lifestyle, nutritional, and hormonal factors, this suggests that common factors, possibly genetic factors, might also influence the coupled maintenance of appendicular muscle mass and FN BMD in adult men.

Key words: population studies - femoral neck bone mineral density - muscle strength men - aging 


\section{Introduction}

At least one third of hip fractures occur in men (Jones et al., 1994), resulting in increased debility and increased mortality (Trombetti et al., 2002). Low femoral neck bone mineral density (FN BMD), reflecting in part low thickness of femoral neck cortices, is one of the main risk factors for hip fracture in men (Rivadeneira et al., 2007). Age of men experiencing hip fractures tends to increase in most countries, suggesting the necessity to investigate factors that might be able to prevent FN BMD loss in adult and older men (Looker et al., 2009; Leslie et al., 2009).

After reaching peak bone mass at about the age of 20 to 30 years, men maintain a stable bone density, before experiencing substantial age-related decrease in FN BMD (Wishart et al., 1995). Acquisition of the skeletal mass in men seems strongly determined by genetic and ethnic factors (Seeman et al., 1996), and by hormonal and lifestyle factors, including tobacco, alcohol consumption, and physical activity (Deng et al., 2001; Gallagher et al., 1997; Pettersson et al., 1999). Indeed, load-bearing exercises in boys are able to increase muscle mass and muscle strength and to have a positive and sustained influence on peak bone mass at the hip (Gunter et al., 2008), suggesting that bone mass and architecture of teenage males is in part physiologically adjusted to control the strains produced by mechanical loading (Frost et al., 1999; Parfitt et al., 2004). The capacity of the skeleton to adapt to mechanical stress remains significant in adults also (Ma et al., 2009), but it tends to decrease with aging (Frost et al., 1999).

A few studies have shown that the appendicular skeletal muscle mass (ASM), more than leg muscle mass, is associated with FN BMD in adult and older men, suggesting a possible musclebone unit at the appendicular level (Szulc et al., 2005; Baumgartner et al., 1996; Pluijm et al., 2001). Since muscle strength and other possible confounders were not measured altogether in these studies, it remains to be determined whether the relationship between the relative ASM 
(RASM; ASM/body height) and bone mass observed in adult and older men is the reflection of the effect on the femoral neck of strains exerted by muscles, the influence of lifestyle, nutritional, and hormonal factors, or is in fact independent of all these factors, thus lending support to the growing evidence of an underlying genetic component in the senescence of the muscle-bone unit in men (Karasik et al., 2008).

To explore this issue, we assessed the relationship between FN BMD and RASM in healthy men with a wide range of ages, taking into account grip and maximum quadriceps strength, body mass, and past and current physical activities, considered as markers of skeletal loading, and adjusted our analyses for numerous hormonal and lifestyle factors known to influence bone and muscle mass in men.

\section{Materials and methods}

\subsection{Participants}

The present study included healthy men aged 20 to 72 years whose mother or grandmother had been included in the EPIDOS (Epidemiology of Osteoporosis) study in Montpellier in Southern France. The EPIDOS study was a cohort of women aged 75 and over, recruited using voter-registration rolls and enrolled in 1992-1993 in a multicenter prospective study on hip fracture risk factors (Dargent-Molina et al., 1996).

Inclusion criteria in the present study were Caucasian individuals in apparent good health, non-institutionalized, and functionally independent. Subjects were excluded if they met any of the following criteria: (i) known metabolic bone disease, (ii) rheumatoid arthritis and/or physician-diagnosed osteoarthritis, (iii) ischaemic heart disease, (iv) previous joint surgery or 
cerebral disease affecting the lower limb, (v) or medication known to affect the musculoskeletal system (corticosteroids, anti-osteoporotic drugs, androgens or anti-androgen drugs, in particular). All subjects included in the present study gave their written informed consent to participate in the study, which was approved by the Human Subjects Research Committee of our University Hospital.

Based on the results of the literature (Szulc et al., 2005; Baumgartner et al., 1996; Pluijm et al., 2001), we expected a correlation coefficient of 0.3 between RASM and FN BMD in our sample. With an alpha risk of 0.05 and a power equal to 0.90 , with a bilateral hypothesis, a sample size of 112 healthy men was sufficient to assess the significance of the relationship between RASM and FN BMD. The present study included 160 healthy men.

\subsection{Osteodensitometric Parameters}

BMD at the right femoral neck (FN BMD), lean mass (excluding bone mineral content), and fat mass for the whole body and specific regions were measured by dual-energy X-ray absorptiometry (DXA) (Hologic QDR-1500 device, Hologic, Waltham, MA, USA). The coefficient of variation for our device during measurement on a standard phantom is less than $3 \%$ for FN BMD and whole body fat and lean mass. Appendicular skeletal muscle mass (ASM) was calculated as the sum of the lean soft tissue in both the right and left arms and legs measured by DXA, as described previously (Szulc et al., 2005), and the relative skeletal muscle mass index (RASM) was calculated as ASM (kg)/body height (cm). 


\subsection{Muscle strength assessments}

Strength measurements were performed once, at the same time of day to minimize any effect of diurnal variation. After a warm-up session, maximum strength performance was examined in the same order for all subjects: maximum grip strength and then isometric maximum knee extension strength (KES).

The right isometric KES was assessed using a load-cell recording device (Captels, St Mathieu de Tréviers, France) firmly attached to the metal framework of a chair and connected to a simple software sampling at $80 \mathrm{~Hz}$. During assessment, subjects were seated on the chair with the back and thigh well supported (hip angle at $90^{\circ}$ ), hands resting on their thighs, the feet free, and the knee passively drawn into a $60^{\circ}$ flexion. A soft cuff, attached via an adjustable nonelastic metal cord to the 500-kg load cell, was fitted with velcro just above the right ankle. Patients were asked to extend their right knee as forcefully as they could for five seconds, and the maximum KES in kilograms was recorded. The length of the test lever arm was measured from the knee joint center to the midpoint of the soft cuff (the distance between the soft cuff and the right ankle was similar for every subject at every session), with the direction of pull being in line with the force transducer. The results of the maximum KES measurements were expressed as the mean knee extension torque obtained by multiplying maximum KES by the lever arm length for each subject and expressed in kilograms $\times$ meters. Scores were the mean of the three maximum trials.

Grip strength was measured using the JAMAR (Smith and Nephew, Memphis, TN) dynamometer, calibrated as described previously (Bohannon et al., 1989), and used according to the recommendations of the American Society of Hand Therapists (Fess et al., 1992). The second 
handle setting was used for all participants (Firrell et al., 1996). For each visit, we recorded three maximal trials, and scores were the mean of the three peak grip strength values recorded in kilograms.

In 97 subjects aged 23-90, different from those included in the present study, KES and grip strength were measured in triplicate on three occasions separated by one week. Under the same conditions as those used in the present study, the intraclass correlation coefficients for grip strength and KES were more than 0.95 and the intrarater coefficients of variation were less than 10\% (Blain et al., 2006).

Assays

Fasted morning blood samples were collected. Serum concentrations of E2 were measured using an enzyme immunoassay sandwich method with a final fluorescent detection (ELFAVidas, Biomerieux SA, France). The lower limit of detection of our E2 assay was $9 \mathrm{pg} / \mathrm{ml}$ (32 pmol/L). IGF-I (Diagnostic systems Laboratories, Webster, USA) and intact PTH (Diasorin, Ctillwater, MN) were determined by immunoradiometric assay. Free testosterone (non-extraction method, Diagnostic Systems Laboratories, Texas, USA), SHBG (CIS Bio International, France), DHEAS (Beckman Coulter, USA), and 25(OH) vitamin D (IDS RIA, France) were determined by RIA (intra-assay variation between 6.3 to $7.1 \%$, inter-assay variation between 3.4 to $13.5 \%$ ). A standard colorimetric dry chemistry assay was used to measure serum creatinine and albumin (Synchron CX5 Automate, Beckman Coulter, Villepinte, France).

\subsection{Other Variables}

The subjects were weighed with an electronic scale to the nearest $0.1 \mathrm{~kg}$, and their height was measured to the nearest $0.1 \mathrm{~cm}$ at the time of muscle strength assessment. Dietary calcium intake 
was estimated with a food-frequency self-administered questionnaire (Fardellone et al., 1991), assessing intake of 20 common foods rich in calcium over the past week. The mean values were expressed in milligrams per day. Tobacco smoking was recorded in two categories: smokers (current and past, one year or more) and non-smokers. Subjects were divided into two categories on the basis of their alcohol consumption: light drinkers (daily consumption of less than onequarter liter of wine or beer, or less than one glass of liquor) and heavy drinkers (daily consumption of more than one-quarter liter of wine or beer, or more than one glass of liquor). The recent and past physical activities were assessed using the QUANTAP system, a standardized and structured computer-assisted interview tool designed to assess lifetime physical activity (Vuillemin et al., 2000), converted into metabolic equivalents (METs) per week (Ainsworth et al., 2000).

\subsection{Statistical Analyses}

The characteristics of the men entered in the present study were described with proportions for categorical variables and with means and standard deviation values for continuous variables. The distributions were tested with Shapiro-Wilk statistics. The relationships between FN BMD and RASM with independent variables were assessed using Pearson or Spearman's rank correlation coefficient when the continuous variables were normally or not normally distributed, respectively, and using Student's t-test for categorical ones. The linearity of the relation between FN BMD and the continuous variables was verified. The collinearity of variables and RASM was also analyzed. To determine factors independently associated with FN BMD, variables significantly associated with FN BMD in the univariate analysis $(\mathrm{p}<0.1)$ and not collinear with RASM were entered in a multivariate analysis using a linear regression model. A forward 
selection was used to enter the variables in the model. $\mathrm{R}^{2}$ criterion was used to select each one. As appendicular skeletal muscle mass but not FN BMD was adjusted for body size, the same analyses were performed when entering body size in the final model and when studying the relationship between FN BMD/body height and RASM. The statistical software SAS (1) version 9.1 was used for this analysis.

\section{Results}

The characteristics of the 160 men participating in the study are displayed in Table 1 . Table 2 displays non-adjusted correlations of FN BMD and RASM with the different covariates. The correlation between FN BMD and RASM (that includes upper and lower limb muscle mass) was of slightly greater magnitude than that between FN BMD and the relative upper limb muscle mass and between FN BMD and the relative leg muscle mass $(r=0.39 ; p<0.001$ versus $r=$ 0.36; $\mathrm{p}<0.001$ and $\mathrm{r}=0.34 ; \mathrm{p}<0.001$, respectively). Factors associated with FN BMD in the univariate analysis (with $\mathrm{p}<0.1$ ), except body mass and body lean mass, that were found to be collinear with RASM, and body height, that was used for the calculation of RASM, were proposed to explain FN BMD in the multiple linear regression model.

Factors associated with FN BMD in the multiple linear regression model are reported in Table 3. RASM remains significantly associated with FN BMD, independently of age, indices of skeletal loading (physical activities, and grip and knee extension strength) and other tested variables, explaining $15 \%$ of FN BMD variance. The other variables independently associated with FN BMD were age (10\% of FN BMD variance), physical activities between 11-20 years (5\% of FN BMD variance), and blood PTH, creatinine, and IGF-I (2\%, 1\%, and 2\% of FN BMD 
variance, respectively). On the whole, the present model explains 35\% of FN BMD variance. When body height was introduced into the multivariate linear regression analysis, the relationship between RASM and FN BMD also remained significant ( $p$ value $<0.0001$ ). The relationship between FN BMD/body height and RASM was also significant in the univariate analysis (Pearson correlation coefficient $=0.32 ; \mathrm{p}<0.0001$ ) and in the multivariate linear regression analysis (data not shown).

\section{Discussion}

The main result of the present study is that RASM is the strongest factor associated with FN BMD in healthy adults aged 20 to 72 years. Since this relationship appears to be independent of age, indices of appendicular skeletal loading, and numerous lifestyle and hormonal parameters, the present study supports the growing evidence that other common factors, including genetic factors, may influence the maintenance with aging of both appendicular skeletal muscle mass and femoral neck BMD in adult men (Karasik et al., 2008).

In children, the gain in height precedes the gain in muscle mass, that precedes the gain in bone mass, suggesting a physiological adaptation of bone to muscle in the growing skeleton (Rauch et al., 2004). If bodily growth and consequently bone mass accrual are to a great extent determined by genetic factors (Parfitt et al., 2004), active children have a greater total body BMD than their inactive peers (Bailey et al., 1999) and an increased hip peak bone mass (Gunter et al., 2008), suggesting a sustained osteotrophic effect of physical activity during growth. Our results are in line with this hypothesis, since physical activity performed during the age of 11-20 years is significantly associated with FN BMD in healthy grown-ups and older men, explaining about 5\% of the variance of their FN BMD. 
Appendicular muscle mass is significantly associated with FN BMD in men aged 50 years or older, and this relationship is independent of physical activity, body mass, and other covariates, suggesting a systemic component of the relationship between RASM and FN BMD (Szulc et al., 2005). Since muscle strength and other possible confounders were not measured in this study nor in others, the authors could not conclude as to whether the relationship between ASM and FN BMD can be explained by the strains exerted by appendicular muscles or by other factors, independent of the habitual appendicular skeletal loading. Melton et al. showed that changes in habitual load (estimated by body mass, appendicular muscle mass, and habitual physical activities) and change in bone strength at the femoral neck in men younger or older than 50 years are not parallel, suggesting that reduced skeletal loading may not be a strong determinant of agerelated bone loss in men (Melton et al., 2006). In addition, the age-related decline of lean mass observed in men seems in part independent of the age-related decline of muscle strength (Morley et al., 2001) and physical activity (Proctor et al., 2000). A plausible hypothesis is therefore that the relationship between RASM and FN BMD in adult men is independent of skeletal loading, which may explain why the effects of various exercise regimens on BMD, although not negligible, have often been found to be weak in healthy adult subjects (Suominen et al., 2006).

Several results in the present study support this hypothesis. RASM that includes upper and lower limb muscle mass was found to be slightly better correlated with FN BMD than was the relative upper limb muscle mass or the relative leg muscle mass, suggesting that the relationship between muscle mass and FN BMD may not only be due to a site-specific effect of skeletal loading in healthy adult men but may involve systemic factors influencing both appendicular bone and muscle mass. 
Furthermore, we found that the relationship between RASM and FN BMD was independent of markers of habitual skeletal loads, including current and long-term leisure time physical activities, knee extension and grip strength, and other possible confounders. The relationship between FN BMD and RASM was also found to be independent of body height, suggesting that this relationship was not due to differences in skeletal size. Taken together, these results suggest that common factors, other that age, body height, skeletal loading, and hormonal and lifestyle factors measured herein may be involved in the maintenance of both FN BMD and RASM in adult men.

Several hypotheses may explain the present results. Genetic factors account for most of the correlation between bone mass and muscle mass in adolescents (Schoenau et al., 2002) and in twins (Seeman et al., 1996). This has been interpreted as an effect of natural selection to ensure that bone strength is closely matched to the strains developed by muscles (Parfitt et al., 2004). The results presented herein suggest that this so-called "muscle-bone unit" may persist after growth has ceased in healthy men of a wide range of ages, supporting the concept of a persistent "evolutionary adaptation" of bone mass to muscle mass in adult men, independently of the "physiologic adaptation" of bone and muscle strength to skeletal loading (Frost et al., 1999). The role of genes in the relationship between RASM and FN BMD is plausible since the resemblance of FN BMD between adult sons and their parents has been shown to be mediated in part by the resemblance of their lean mass, and this, independently of shared lifestyle habits, including physical activity (Blain et al., 2006). The fact that genes encoding for the androgen receptor and the estrogen receptor alpha may influence both bone mass and body composition in male mice (Callewaert et al., 2009a; Callewaert et al., 2009b) supports this hypothesis. Factors other than those taken into account in the present study might also be involved in the relationship between 
RASM and FN BMD. These factors include inflammatory factors since the age-related increase in pro-inflammatory cytokines is associated with sarcopenia (Schaap et al., 2006) and bone resorption (Lauretani et al., 2006) in older men. Nutritional factors, other than those measured herein, such as protein intake, or the intake of fatty acids for example, might also be involved in the relationship between RASM and FN BMD in adult men (Coin et al., 2008).

The present study shows that age (which explains $10 \%$ of FN BMD in our model), serum IGF-I and PTH (which explain 2\% of FN BMD variance), and serum creatinine (which explains $1 \%$ of FN BMD variance) were significantly associated with FN BMD in our sample of adult men. These results are in line with those of previous studies supporting the role of IGF-1 and PTH in FN BMD maintenance in men (Blain et al., 2004; Cheung et al., 2005). Our results suggest, however, that the effect of IGF-I and PTH is of low magnitude when muscle mass, age, muscle strength, lifestyle factors, and other biomarkers are included in the multivariate model. In accordance with previous studies conducted in healthy and well-nourished men with a moderate consumption of alcohol and tobacco, none of the hormonal factors assessed in the present study (neither E2, free testosterone, SGHG), nor vitamin D, calcium intake, or alcohol and tobacco consumption were significantly associated with FN BMD in the final model (Cheung et al., 2005).

In our study, we measured the main hormonal factors known to be significantly involved in the muscle-bone unit (Zofkova et al. 2008). It remains to be determined whether other hormonal factors such as insulin production and sensitivity, for example, are also involved in the relationship between RASM and FN BMD (Fernández-Real et al., 2009).

Although our final model includes muscle mass, age, muscle strength, and numerous lifestyle factors and biomarkers, it accounts for only $35 \%$ of the variance in FN BMD. Because 
heritability estimates may explain more than $60 \%$ of the variance of appendicular lean mass and hip bone mass (Peacock et al., 2005; Hsu et al., 2005), a significant part of the $65 \%$ that remains unaccounted for in the present study may be ascribed to genetic factors. However, further studies are required to assess whether taking into account nutritional factors, inflammatory parameters, and hormonal factors other than those measured herein would improve the prediction of FN BMD in men. In addition, measurements of maximum knee extension and grip strength should only be considered as indirect measures of potential mechanical loading by muscles on the hip since the muscles involved in these measurements do not have attachments to the femoral neck. It remains therefore to be determined also whether a better assessment of loads usually applied on the hip in men would improve the prediction of FN BMD in men.

Three potentially important messages can be drawn from the present study. First, our results support the hypothesis that promoting physical activity during hip bone accrual and implementing measures to prevent renal failure, low levels of IGF-I, and hyperparathyroidism during adulthood may help to maintain FN BMD in adult men. Second, RASM measured with DXA in the present study was found to be the strongest factor associated with FN BMD in our sample of adult men, explaining $15 \%$ of the variance of FN BMD. RASM measured by DXA can be predicted when measuring calf circumference (Rolland et al., 2003), mid-upper-arm muscular circumference and arm muscle area (which are derived from the mid-upper-arm muscular circumference and the triceps skinfold) (Frisancho et al., 1990), or when using a more complex equation based on body mass, body height, hip circumference, and grip strength for example (Baumgartner et al., 1998). Further studies are necessary to determine whether RASM, assessed by anthropometric methods, would be useful in the screening of adult men at risk of low FN BMD. Third, since the relationship between RASM and FN BMD seems to be in great part 
independent of age and loading indices, here again further studies are needed to better understand which factors, including genetic ones, are involved in the coupled RASM-FN BMD maintenance in adult men.

The main strength of the present study is that several indices of appendicular skeletal loading, including grip and maximum knee extension strength, body mass, and lifetime physical activity, and numerous possible hormonal and lifestyle confounders have been measured to adjust the relationship between RASM and FN BMD in a relatively large sample of well-characterized healthy men with a wide range of ages.

Some limitations of our results should be noted, and several questions remain to be answered. Our study is cross-sectional, reflecting associations but not revealing causes and effects. Isometric knee extension strength, body mass, and physical activity are only surrogate estimates of the strains applied on the hip. We have confidence in our results since the questionnaire we used to quantify physical activities was sufficiently sensitive to show a relationship between physical activities exerted over the age range of 11-20 years and $F N \mathrm{BMD}_{2}$ and failed to show any significant relationships between FN BMD and physical activities exerted over the past five and ten years before entering the study. Besides, maximum quadriceps strength and grip strength are considered as good and reproducible indicators of aberrant loads that may have an influence on the maintenance of the skeleton (Lanyon et al., 2001). There is a potential for selection bias in the current study, as healthier subjects are more likely to respond and participate in this type of study. Our results are therefore only valuable for a Caucasian population of healthy men. For ethical reasons, patients with osteoarthritis that were considered by their physicians to be sufficiently symptomatic to possibly influence their maximum extension strength were not included in the present study. In addition, osteoarthritis has a complex and specific influence on 
hip bone density. Indeed, if a reduction in physical activities is most often associated with a loss of proximal femur BMD, subjects with symptomatic osteoarthritis have marked loss of muscle mass and strength but an increased BMD at the proximal femur (Suetta et al., 2007, Chaganti et al., 2010). Since elderly men with osteoarthritis at the lower limbs represent a large population, further studies are needed to determine whether our results are applicable to men with osteoarthritis. Another limitation is the accuracy of the evaluation of ASM by DXA, which might underestimate the age-related decrease of the muscle mass (Proctor et al., 1999). However, measurement errors of ASM may have underestimated the correlation between RASM and FN BMD in our sample of men with a wide range of ages.

In conclusion, the present study shows that RASM, with ASM measured by DXA, is the strongest factor associated with FN BMD in men of a wide range of ages, suggesting that RASM estimates by anthropometric methods may help screening men at risk for low FN BMD. Since the relationship between RASM and FN BMD is independent of indices of appendicular skeletal loading and numerous estimators of hormonal status and lifestyle, the present study suggests that common factors, including possibly genetic factors, may be involved in the coupled maintenance with aging of RASM and FN BMD in adult and older men.

\section{Acknowledgements}

Funding for this research was provided by the French Ministry of Health (Projet Hospitalier de Recherche Clinique, 1998, UF-7606). The authors acknowledge Ms. Muriel Fernandez, Ms. Claire Belloc, Dr. Rachida Louahem, and Dr. Claude Jeandel, for help in data collection, and Sharon Lynn Salhi, $\mathrm{PhD}$, for editorial assistance. 


\section{References}

Ainsworth, B.E., Haskell, W.L., Whitt, M.C., Irwin, M.L., Swartz, A.M., Strath, S.J., O'Brien, W.L., Bassett, D.R. Jr., Schmitz, K.H., Emplaincourt, P.O., Jacobs, D.R. Jr., Leon, A.S., 2000. Compendium of physical activities: an update of activity codes and MET intensities. Med. Sci. Sports Exerc. 32, S498-504.

Bailey, D.A., McKay, H.A., Mirwald, R.L., Crocker, P.R., Faulkner, R.A., 1999. A six-year longitudinal study of the relationship of physical activity to bone mineral accrual in growing children: the university of Saskatchewan bone mineral accrual study. J. Bone Miner. Res. 14, 1672-1679.

Baumgartner, R.N., Stauber, P.M., Koehler, K.M., Romero, L., Garry, P.J., 1996. Associations of fat and muscle masses with bone mineral in elderly men and women. Am. J. Clin. Nutr. 63, 365-372.

Baumgartner, R.N., Koehler, K.M., Gallagher, D., Romero, L., Heymsfield, S.B., Ross, R.R., Garry, P.J., Lindeman, R.D., 1998. Epidemiology of sarcopenia among the elderly in New Mexico. Am. J. Epidemiol. 147, 755-763.

Blain, H., Carrière, I., Péninou, G., Micallef, J.P., Colvez, A., 2006. Reliability of a new instrument for measuring maximum rising strength. Am. J. Phys. Med. Rehabil. 85, 502508.

Blain, H., Vuillemin, A., Blain, A., Guillemin, F., De Talance, N., Doucet, B., Jeandel, C., 2004. Age-related femoral bone loss in men: evidence for hyperparathyroidism and insulin-like growth factor-1 deficiency. J. Gerontol. A. Biol. Sci. Med. Sci. 59, 1285-1289.

Blain, H., Vuillemin, A., Jeandel, C., Jouanny, P., Guillemin, F., Le Bihan, E., 2006. Lean mass plays a gender-specific role in familial resemblance for femoral neck bone mineral density in adult subjects. Osteoporos. Int. 17, 897-907.

Bohannon, R.W., Andrews, A.W., 1989. Accuracy of spring and strain gauge hand-held dynamometers. J. Orthop. Sport. Phys. Ther. 10, 323-325.

Callewaert, F., Bakker, A., Schrooten, J., Van Meerbeek, B., Verhoeven, G., Boonen, S., Vanderschueren, D., 2009. Androgen Receptor Disruption Increases the Osteogenic Response to Mechanical Loading in Male Mice. J. Bone Miner. Res. In Press.

Callewaert, F., Venken, K., Ophoff, J., De Gendt, K., Torcasio, A., van Lenthe, G.H., Van Oosterwyck, H., Boonen, S., Bouillon, R., Verhoeven, G., Vanderschueren, D., 2009. Differential regulation of bone and body composition in male mice with combined inactivation of androgen and estrogen receptor-alpha. FASEB J. 23, 232-240.

Chaganti, R.K., Parimi, N., Lang, T., Orwoll, E., Stefanick, M.L., Nevitt, M., Lane, N.E., for the Osteoporotic Fractures in Men (MrOS) Study Group., 2010. Bone mineral density and prevalent osteoarthritis of the hip in older men for the Osteoporotic Fractures in Men (MrOS) Study Group. Osteoporos. Int. In Press.

Cheung, E.Y., Ho, A.Y., Lam, K.F., Tam, S., Kung, A.W. 2005. Determinants of bone mineral density in Chinese men. Osteoporos. Int. 16:1481-1486.

Coin, A., Perissinotto, E., Enzi, G., Zamboni, M., Inelmen, E.M., Frigo, A.C., Manzato, E., Busetto, L., Buja, A., Sergi, G., 2008. Predictors of low bone mineral density in the elderly: the role of dietary intake, nutritional status and sarcopenia. Eur. J. Clin. Nutr. 62, 802-809. 
Dargent-Molina, P., Favier, F., Grandjean, H., Baudoin, C., Schott, A.M., Hausherr, E., Meunier, P.J., Bréart, G., 1996. Fall-related factors and risk of hip fracture: the EPIDOS prospective study. Lancet 348, 145-149.

Deng, H.W., Lai, D.B., Conway, T., Li, J., Xu, F.H., Davies, K.M., Recker, R.R., 2001. Characterization of genetic and lifestyle factors for determining variation in body mass index, fat mass, percentage of fat mass, and lean mass. J. Clin. Densitom. 4, 353-361.

Fardellone, P., Sebert, J.L., Bouraya, M., Bonidan, O., Leclerq, G., Doutrellot, C., Bellony, R., Dubreuil, A., 1991. Evaluation of the calcium content of diet by frequential selfquestionnaire. Rev. Rhum. Mal. Osteoartic. 58, 99-103.

Fernández-Real, J.M., Izquierdo, M., Ortega, F., Gorostiaga, E., Gómez-Ambrosi, J., MorenoNavarrete, J.M., Frühbeck, G., Martínez, C., Idoate, F., Salvador, J., Forga, L., Ricart, W., Ibañez, J., 2009. The relationship of serum osteocalcin concentration to insulin secretion, sensitivity, and disposal with hypocaloric diet and resistance training. J. Clin. Endocrinol. Metab. 94, 237-45.

Fess, E.E. 1992. Grip strength. In: J.S. Casanova, Editor, Clinical assessment recommendations (2nd ed.). American Society of Hand Therapists, Chicago, 41-45.

Firrell, J., Crain, G.M., 1996. Which setting of the dynamometer provides maximal grip strength? J. Hand Surg. 21A, 397-401.

Frisancho, A.R., 1990. Anthropometric standards for the assessment of growth and nutritional status. University of Michigan Press, Ann Arbor.

Frost, H.M., 1999. Changing views about "osteoporoses", a 1998 overview. Osteoporos. Int. $10,345-352$.

Gallagher, D., Visser, M., De Meersman, R.E., Sepúlveda, D., Baumgartner, R.N., Pierson, R.N., Harris, T., Heymsfield, S.B., 1997. Appendicular skeletal muscle mass: effects of age, gender, and ethnicity. J. Appl. Physiol. 83, 229-239.

Gunter, K., Baxter-Jones, A.D., Mirwald, R.L., Almstedt, H., Fuchs, R.K., Durski, S., Snow, C., 2008. Impact exercise increases BMC during growth: an 8-year longitudinal study. J. Bone Miner. Res. 23, 986-993.

Hsu, F.C., Lenchik, L., Nicklas, B.J., Lohman, K., Register, T.C., Mychaleckyj, J., Langefeld, C.D., Freedman, B.I., Bowden, D.W., Carr, J.J., 2005. Heritability of body composition measured by DXA in the diabetes heart study. Obes. Res. 13, 312-319.

Jones, G., Nguyen, T., Sambrook, P.N., Kelly, P.J., Gilbert, C., Eisman, J.A., 1994. Symptomatic fracture incidence in elderly men and women: the Dubbo Osteoporosis Epidemiology Study (DOES). Osteoporos. Int. 4, 277-282.

Karasik, D., Kiel, D.P., 2008. Genetics of the musculoskeletal system: a pleiotropic approach. J. Bone Miner. Res. 23, 788-802.

Lanyon, L., Skerry, T., 2001. Postmenopausal osteoporosis as a failure of bone's adaptation to functional loading: a hypothesis. J. Bone. Miner. Res. 16, 1937-1947.

Lauretani, F., Bandinelli, S., Russo, C.R., Maggio, M., Di Iorio, A., Cherubini, A., Maggio, D., Ceda, G.P., Valenti, G., Guralnik, J.M., Ferrucci, L., 2006. Correlates of bone quality in older persons. Bone 39, 915-921.

Leslie, W.D., O'Donnell, S., Jean, S., Lagacé, C., Walsh, P., Bancej, C., Morin, S., Hanley, D.A., Papaioannou, A., 2009. Osteoporosis Surveillance Expert Working Group. Trends in hip fracture rates in Canada. JAMA. 302, 883-889. 
Looker, A.C., Melton, L.J., Harris, T.B., Borrud, L.G., Shepherd, J.A., 2009. Prevalence and Trends in Low Femur Bone Density Among Older US Adults: NHANES 2005-2006 Compared with NHANES III dagger. J. Bone Miner. Res. In Press.

Ma, H., Leskinen, T., Alen, M., Cheng, S., Sipilä, S., Heinonen, A., Kaprio, J., Suominen, H., Kujala, U.M., 2009. Long-term leisure time physical activity and properties of bone: a twin study. J. Bone Miner. Res. 24, 1427-1433.

Melton, L.J. 3rd, Riggs, B.L., Achenbach, S.J., Amin, S., Camp, J.J., Rouleau, P.A., Robb, R.A., Oberg, A.L., Khosla, S., 2006. Does reduced skeletal loading account for age-related bone loss? J. Bone Miner. Res. 21, 1847-55.

Morley, JE., Baumgartner, R.N., Roubenoff, R., Mayer, J., Nair, K.S., 2001. Sarcopenia. J. Lab. Clin. Med. 137, 231-243.

Parfitt, A.M., 2004. Perspective. Attainment of peak bone mass: what is the relationship between muscle growth and bone growth ? Bone 34, 767-770.

Peacock, M., Koller, D.L., Fishburn, T., Krishnan, S., Lai, D., Hui, S., Johnston, C.C., Foroud, T., Econs, M.J., 2005. Sex-specific and non-sex-specific quantitative trait loci contribute to normal variation in bone mineral density in men. J. Clin. Endocrinol. Metab. 90, 3060-3066.

Pettersson, U., Nordström, P., Lorentzon, R., 1999. A comparison of bone mineral density and muscle strength in young male adults with different exercise level. Calcif. Tissue. Int. 64, 490-498.

Pluijm, S.M., Visser, M., Smit, J.H., Popp-Snijders, C., Roos, J.C., Lips, P., 2001. Determinants of bone mineral density in older men and women: body composition as mediator. J. Bone Miner. Res. 16, 2142-2151.

Proctor, D.N., Melton, L.J., Khosla, S., Crowson, C.S., O'Connor, M.K., Riggs, B.L., 2000. Relative influence of physical activity, muscle mass and strength on bone density. Osteoporos. Int. 11, 944-952.

Proctor, D.N., O'Brien, P.C., Atkinson, E.J., Nair, K.S., 1999. Comparison of techniques to estimate total body skeletal muscle mass in people of different age groups. Am. J. Physiol. 277, E489-495.

Rauch, F., Bailey, D.A., Baxter-Jones, A., Mirwald, R., Faulkner, R., 2004. The 'muscle-bone unit' during the pubertal growth spurt. Bone 34, 771-775.

Rivadeneira, F., Zillikens, M.C., De Laet, C.E., Hofman, A., Uitterlinden, A.G., Beck, T.J., Pols, H.A., 2007. Femoral neck BMD is a strong predictor of hip fracture susceptibility in elderly men and women because it detects cortical bone instability: the Rotterdam Study. J. Bone Miner. Res. 22, 1781-1790.

Rolland, Y., Lauwers-Cances, V., Cournot, M., Nourhashémi, F., Reynish, W., Rivière, D., Vellas, B., Grandjean, H., 2003. Sarcopenia, calf circumference, and physical function of elderly women: a cross-sectional study. J. Am. Geriatr. Soc. 51, 1120-1124.

Schaap, L.A., Pluijm, S.M., Deeg, D.J., Visser, M., 2006. Inflammatory markers and loss of muscle mass (sarcopenia) and strength. Am. J. Med. 119, 526.e9-17.

Schoenau, E., Frost, H.M., 2002. The "muscle-bone unit" in children and adolescents. Calcif. Tissue Int. 70, 405-407.

Seeman, E., Hopper, J.L., Young, N.R., Formica, C., Goss, P., Tsalamandris, C., 1996. Do genetic factors explain associations between muscle strength, lean mass, and bone density? A twin study. Am. J. Physiol. 270, E320-327. 
Sneve, M., Emaus, N., Joakimsen, R.M., Jorde, R., 2008. The association between serum parathyroid hormone and bone mineral density, and the impact of smoking: the Tromso Study. Eur. J. Endocrinol. 158, 401-409.

Suetta, C., Aagaard, P., Magnusson, S.P., Andersen, L.L., Sipilä, S., Rosted, A., Jakobsen, A.K., Duus, B., Kjaer, M., 2007. Muscle size, neuromuscular activation, and rapid force characteristics in elderly men and women: effects of unilateral long-term disuse due to hiposteoarthritis. J. Appl. Physiol. 102, 942-948.

Suominen, H., 2006. Muscle training for bone strength. Aging Clin. Exp. Res. 18:85-93.

Szulc, P., Beck, T.J., Marchand, F., Delmas, P.D., 2005. Low skeletal muscle mass is associated with poor structural parameters of bone and impaired balance in elderly men--the MINOS study. J. Bone Miner. Res. 20, 721-729.

Trombetti, A., Herrmann, F., Hoffmeyer, P., Schurch, M.A., Bonjour, J.P., Rizzoli, R., 2002. Survival and potential years of life lost after hip fracture in men and age-matched women. Osteoporos. Int. 13, 731-737.

Vuillemin, A., Guillemin, F., Denis, G., Huot, J., Jeandel, C., 2000. A computer-assisted assessment of lifetime physical activity: reliability and validity of the QUANTAP software. Rev. Epidemiol. Santé Publique 48, 157-167.

Wishart, J.M., Need, A.G., Horowitz, M., Morris, H.A., Nordin, B.E.C., 1995. Effect of age on bone density and bone turnover in men. Clin. Endocrinol. 42, 141-146.

Zofková, I., 2008. Hormonal aspects of the muscle-bone unit. Physiol. Res. 57 Suppl 1, S159169. 
Table 1. Characteristics of the study population $(n=160)$

\begin{tabular}{|c|c|}
\hline & Mean $\pm S D$ \\
\hline Age (years) & $45.6 \pm 15.7$ \\
\hline FN BMD $\left(\mathrm{g} / \mathrm{cm}^{2}\right)$ & $0.862 \pm 0.128$ \\
\hline Relative appendicular skeletal muscle mass $(\mathrm{kg} / \mathrm{cm})$ & $0.150 \pm 0.016$ \\
\hline Body height $(\mathrm{cm})$ & $174.7 \pm 6.2$ \\
\hline Body mass $(\mathrm{kg})$ & $79.0 \pm 11.8$ \\
\hline Lean mass $(\mathrm{kg})$ & $58.1 \pm 6.3$ \\
\hline Fat mass $(\mathrm{kg})$ & $18.17 \pm 7.00$ \\
\hline Calcium intake (mg/day) & $811 \pm 368$ \\
\hline \multicolumn{2}{|l|}{ Tobacco smoking $[n(\%)]$} \\
\hline Current/past smokers & $\underline{105(65.6 \%)}$ \\
\hline No smokers & $55(34.4 \%)$ \\
\hline \multicolumn{2}{|l|}{ Alcohol consumption } \\
\hline Yes $[n(\%)]$ & $92(57.5 \%)$ \\
\hline No $[n(\%)]$ & $68(42.5 \%)$ \\
\hline Knee extension strength $(\mathrm{Nm})$ & $46.6 \pm 12.4$ \\
\hline Grip strength $(\mathrm{Nm})$ & $47.7 \pm 8.2$ \\
\hline Physical activities (1-10 first years) (METs per week) & $1170 \pm 554$ \\
\hline Physical activities (11-20 first years) (METs per week) & $5415 \pm 2517$ \\
\hline Physical activities over the past five years (METs per week) & $6704 \pm 4741$ \\
\hline Physical activities over the past ten years (METs per week) & $6793 \pm 4577$ \\
\hline Serum calcium $(\mathrm{mmol} / \mathrm{L})$ & $2.38 \pm 0.13$ \\
\hline Serum $25(\mathrm{OH}) \mathrm{D}(\mathrm{nmol} / \mathrm{L})$ & $70.9 \pm 28.0$ \\
\hline Serum creatinine $(\mathrm{mmol} / \mathrm{L})$ & $86.3 \pm 11.8$ \\
\hline Serum albumin $(\mathrm{g} / \mathrm{L})$ & $43.9 \pm 5.3$ \\
\hline Serum PTH (pg/ml) & $21.4 \pm 8.1$ \\
\hline Serum E2 (pmol/L) & $88.9 \pm 33.6$ \\
\hline Serum free testosterone $(\mathrm{ng} / \mathrm{ml})$ & $5.4 \pm 2.2$ \\
\hline Serum DHEAs (mg/ml) & $1.8 \pm 1.1$ \\
\hline Serum IGF-I (ng/ml) & $188.5 \pm 84.0$ \\
\hline Serum SHBG $(\mathrm{nmol} / \mathrm{L})$ & $44.9 \pm 25.1$ \\
\hline
\end{tabular}

Abbreviations: FN, femoral neck; BMD: bone mineral density. 
Table 2. Correlations of RASM and FN BMD with different variables

\begin{tabular}{|c|c|c|c|c|}
\hline \multirow[t]{2}{*}{ Variable (units) } & \multicolumn{2}{|c|}{$F N B M D$} & \multicolumn{2}{|l|}{$R A S M$} \\
\hline & $\frac{\frac{\text { Correlation }}{\text { Coefficient or }}}{\text { mean } \pm S D^{*}}$ & $p$ value** & $\frac{\frac{\text { Correlation }}{\text { Coefficient or }}}{\text { mean } \pm S D^{*}}$ & $p$ value $* *$ \\
\hline Age (years) & -0.355 & $\leq 0.0001$ & $\underline{-0.030}$ & $\underline{0.7004}$ \\
\hline FN BMD $\left(\mathrm{g} / \mathrm{cm}^{2}\right)$ & - & & & \\
\hline Relative appendicular skeletal muscle mass $(\mathrm{kg} / \mathrm{cm})$ & 0.390 & $<0.0001$ & - & - \\
\hline Height $(\mathrm{cm})$ & 0.161 & 0.0418 & 0.283 & 0.0003 \\
\hline Body mass $(\mathrm{kg})$ & 0.209 & 0.0080 & 0.735 & $<0.0001$ \\
\hline Lean mass $(\mathrm{kg})$ & 0.338 & $<0.0001$ & 0.890 & $<0.0001$ \\
\hline Fat mass (kg) & 0.001 & $\underline{0.9314}$ & $\underline{0.418}$ & $\leq 0.0001$ \\
\hline Calcium intake (mg/day) & 0.073 & $\underline{0.3554}$ & $\underline{0.164}$ & $\underline{0.1434}$ \\
\hline Tobacco smoking $($ mean \pm SD) & & & & \\
\hline Current/past smokers $(\mathrm{n}=105)$ & $0.854 \pm 0.121$ & 0.3270 & $0.149 \pm 0.016$ & 0.5260 \\
\hline No smokers $(\mathrm{n}=55)$ & $0.876 \pm 0.141$ & & $0.151 \pm 0.017$ & \\
\hline Alcohol consumption (mean \pm SD) & & & & \\
\hline Light $(\mathrm{n}=92)$ & $0.833 \pm 0.111$ & $<0.0010$ & $0.149 \pm 0.016$ & 0.4400 \\
\hline Heavy $(n=68)$ & $0.900 \pm 0.140$ & & $0.151 \pm 0.017$ & \\
\hline Knee extension strength $(\mathrm{Nm})$ & 0.177 & $\underline{0.0247}$ & $\underline{0.375}$ & $\leq 0.0001$ \\
\hline Grip strength $(\mathrm{Nm})$ & 0.159 & 0.0440 & 0.368 & $<0.0001$ \\
\hline Physical activities (1-10 first years) (METs per week) & 0.248 & $\underline{0.0016}$ & $\underline{0.088}$ & $\underline{0.2678}$ \\
\hline Physical activities (11-20 first years) (METs per week) & 0.216 & $\underline{0.0060}$ & $\underline{0.0463}$ & $\underline{0.5614}$ \\
\hline $\begin{array}{l}\text { Physical activities over the past five years (METs per } \\
\text { week) }\end{array}$ & 0.021 & $\underline{0.7848}$ & $\underline{0.124}$ & $\underline{0.1159}$ \\
\hline $\begin{array}{l}\text { Physical activities over the past ten years (METs per } \\
\text { week) }\end{array}$ & 0.003 & $\underline{0.9677}$ & $\underline{0.159}$ & $\underline{0.0442}$ \\
\hline Serum calcium $(\mathrm{mmol} / \mathrm{L})$ & $\underline{-0.026}$ & $\underline{0.7681}$ & $\underline{-0.084}$ & $\underline{0.2908}$ \\
\hline Serum $25(\mathrm{OH})$ vitamin $\mathrm{D}(\mathrm{nmol} / \mathrm{L})$ & 0.131 & 0.0991 & 0.068 & 0.3913 \\
\hline Serum creatinine $(\mathrm{mmol} / \mathrm{L})$ & 0.144 & 0.0687 & 0.128 & 0.1063 \\
\hline Serum albumin $(g / L)$ & 0.019 & $\underline{0.8146}$ & $\underline{-0.043}$ & $\underline{0.5847}$ \\
\hline Serum PTH (pg/ml) & $\underline{-0.248}$ & $\underline{0.0010}$ & $\underline{0.014}$ & $\underline{0.8578}$ \\
\hline Serum E2 (pmol/L) & 0.104 & 0.1897 & 0.143 & 0.0718 \\
\hline Serum free testosterone $(\mathrm{ng} / \mathrm{ml})$ & 0.045 & $\underline{0.5705}$ & $\underline{-0.179}$ & $\underline{0.0230}$ \\
\hline Serum DHEAS $(\mathrm{mg} / \mathrm{ml})$ & 0.163 & $\underline{0.0394}$ & $\underline{0.100}$ & $\underline{0.2083}$ \\
\hline Serum IGF-I (ng/ml) & 0.172 & $\underline{0.0292}$ & $\underline{0.114}$ & $\underline{0.1526}$ \\
\hline Serum SHBG (nmol/L) & $\underline{-0.135}$ & $\underline{0.0879}$ & $\underline{-0.243}$ & $\underline{0.0019}$ \\
\hline
\end{tabular}

Abbreviations: FN BMD, femoral neck bone mineral density; METs, metabolic equivalents; E2, 17 beta-estradiol; DHEAS. dehydroepiandrosterone sulfate; IGF-I, insulin-like growth factor-1; SHBG, sex hormone-binding globulin. * Values are Pearson or Spearman's rank correlation coefficients between FN BMD (or RASM) and continuous variables or mean FN BMD (or RASM) \pm SD in each subgroup for alcohol consumption and tobacco smoking. ** $\mathrm{P}$ corresponds to the level of significance of the correlation 
coefficients between FN BMD or RASM and continuous variables or to the t-test used to compare means FN BMD (or RASM) between subgroups for alcohol consumption and tobacco smoking. 
Table 3. Multiple linear regression model with variables associated with FN BMD in the univariate analysis

\begin{tabular}{lcccc}
\hline \multicolumn{1}{c}{ Variables } & $\beta$ & $S E(\beta)$ & Cumulative R & $p$ value \\
\hline Appendicular skeletal muscle mass /height & 0.00283 & 0.000523 & 0.15 & $<0.0001$ \\
Age (years) & -0.00356 & 0.000725 & 0.25 & 0.0001 \\
Physical activities (11-20 first years) (METs & 0.00001 & 0.000003 & 0.0020 \\
per week) & -0.00220 & 0.001104 & 0.32 & 0.0480 \\
Serum PTH (pg/ml) & 0.00163 & 0.000734 & 0.0033 & 0.0282 \\
Serum creatinine (ng/ml) & -0.00026 & 0.000128 & 0.0402 \\
Serum IGF-I (ng/ml) & & & 0.35 \\
\hline
\end{tabular}

